\title{
Biosurfactants are useful tools for the bioremediation of contaminated soil: a review
}

\author{
M. Bustamante ${ }^{1}$, N. Durán ${ }^{2,3}$, M. C. Diez ${ }^{4 *}$ \\ ${ }^{1}$ Doctoral Program in Sciences of Natural Resources, Universidad de La Frontera, P. O. B. 54-D, Temuco, Chile. \\ ${ }^{2}$ Instituto de Química, Biological Chemistry Laboratory, Universidade Estadual de Campinas (UNICAMP), $P$. \\ O. B. 6154, 13083-970, Campinas, SP, Brazil. ${ }^{3}$ Center of Natural and Human Sciences, Universidade Federal do \\ ABC, 09210-170, Santo André, SP, Brazil. ${ }^{4}$ Environmental Biotechnology Center, Scientifical and Technological \\ Bioresource Nucleus (BIOREN) and Department of Chemical Engineering, Universidad de La Frontera, P. O. \\ B. 54-D, Temuco, Chile. "Corresponding author: mcdiez@ufro.cl
}

\begin{abstract}
Bioremediation processes are negatively affected by the low aqueous solubility of some contaminants; therefore their bioavailability may be enhanced by the addition of surfactants. These compounds are organic molecules that can be chemically and biologically produced. Surfactants contain both hydrophilic and hydrophobic groups, therefore reducing surface and interfacial tensions of immiscible fluids and increasing the solubility and sorption of hydrophobic organic and inorganic compounds. This article provides an overview of characteristics of natural and synthetic surfactants and the effects of biosurfactants on solubility, sorption and biodegradation of hydrophobic organic contaminants; as well as the effects of biosurfactants on degrader microorganisms as white-rot fungi. Finally, some examples of application of natural surfactants for bioremediation of contaminated soils are shown. In general, this overview indicates the great potential of biosurfactants on the remediation of contaminated sites.
\end{abstract}

Keywords: Biosurfactants, hydrophobic organic compounds, soil. 


\section{Introduction}

Soil pollution is a consequence of the accumulation of a wide range of chemical compounds generated either by natural or industrial processes. The existence of contaminated sites is an important environmental problem today.

Several strategies involving biological, physicochemical, and thermal processes have been developed to remediate contaminated sites (Bollag and Bollag, 1995; Vidali, 2001; Rubilar et al., 2011). Methods such as incineration, excavation, landfilling and storage are expensive, sometimes difficult to execute (Vidali, 2001; Jain et al., 2005), inefficient, and often exchange one problem for another (Bollag and Bollag, 1995). Alternatively, biological processes offer several advantages over conventional technologies, because they are often more environmentally friendly, economic and versatile, and they can reduce the concentration and toxicity of a large number of contaminants (Vidali., 2001; Jain et al., 2005). However, these processes are limited by the low water solubility of the contaminants, limiting their availability to microorganisms (Bollag and Bollag, 1995; Volkering et al., 1998).

Bioavailability of a contaminant is largely controlled by its hydrophobicity and ease of desorption from the solid phase of the soil to the aqueous solution (Semple et al., 2003). The molecular structure, concentration and physico-chemical characteristics of the pollutants limit their bioavailability (Volkering et al., 1998; Alexander, 2000). Low bioavailability is also related to the ageing of the pollutants in the soil (Alexander, 1995; Semple et al., 2003). The addition of a surfactant to a contaminated soil can reduce the interfacial tension thus increasing the mass transfer of the contaminants (Mulligan et al., 2001; Gao et al., 2007; Franzetti et al., 2008). In this context, several researchers have shown that various surfactants can enhance desorption (Aronstein et al., 1991; MataSandoval et al., 2002; Xu et al., 2006), solubilization
(Garon et al., 2002; Prak and Pritchard, 2002; Doong and Lei, 2003), biodegradation of organic compounds (Fava and Di Gioia, 2001; Kim et al., 2001), and removal of heavy metals from soil (Dahrazma and Mulligan, 2007; Rufino et al., 2011).

Thus, the aim of this review is to provide an overview of characteristics of natural surfactant (biosurfactant) and synthetic surfactants (surfactant), the effects of biosurfactants on solubility, sorption and biodegradation of hydrophobic organic contaminants. The effects of biosurfactants on degrader microorganisms and white-rot fungi are also presented. Finally, some examples of application of biosurfactants for bioremediation of contaminated soils are shown.

\section{Characteristics and properties of the surfactants}

The surface activity of surfactants derives from their amphiphilic structure, meaning that their molecules contain both water soluble and water insoluble portions (West and Harwell, 1992). The water solubility of the surfactants is due to the hydrophilic portion (polar group), while the hydrophobic portion (nonpolar chain) tends to concentrate at the air-water interfaces or in the center of micelles, reducing the surface tension of the solution (West and Harwell, 1992; Desai and Banat, 1997; Volkering et al., 1998). Surfactants form aggregates or micelles; this ability confers certain properties such as emulsifying, foaming, dispersing, and the capacity to act as a detergent, making surfactants very versatile chemical compounds. They are applied in several industrial sectors such as the cosmetics, pharmaceuticals and food, petroleum, agrochemical and fertilizer industries, as it has been reviewed by Kosaric (1992), Deleu and Paquot (2004) and Banat et al. (2010). 
Surfactants are characterized by properties such as critical micelle concentration (CMC), hydrophilic-lipophilic balance (HLB), chemical structure and charge, as well as properties from their origin source (Van Hamme et al., 2006). The surfactants exist as monomers or single molecules at low concentration in aqueous solutions; over the $\mathrm{CMC}$, the surfactant molecules assemble together, forming aggregates. The CMC depends on surfactant structure, composition, temperature, ionic strength, and the presence and types of organic additives in the solutions (Fuget et al., 2005). At the CMC of surfactant solutions, a drastic change occurs in many physicochemical properties (surface tension, conductivity, or turbidity) (Figure 1) (Hanna et al., 2005; Zana, 2005). Micelles are capable of dissolving hydrophobic contaminants in their hydrophobic core, which results in an increased apparent aqueous solubility of the pollutants (Edwards et al., 1991; Prak and Pritchard, 2002).

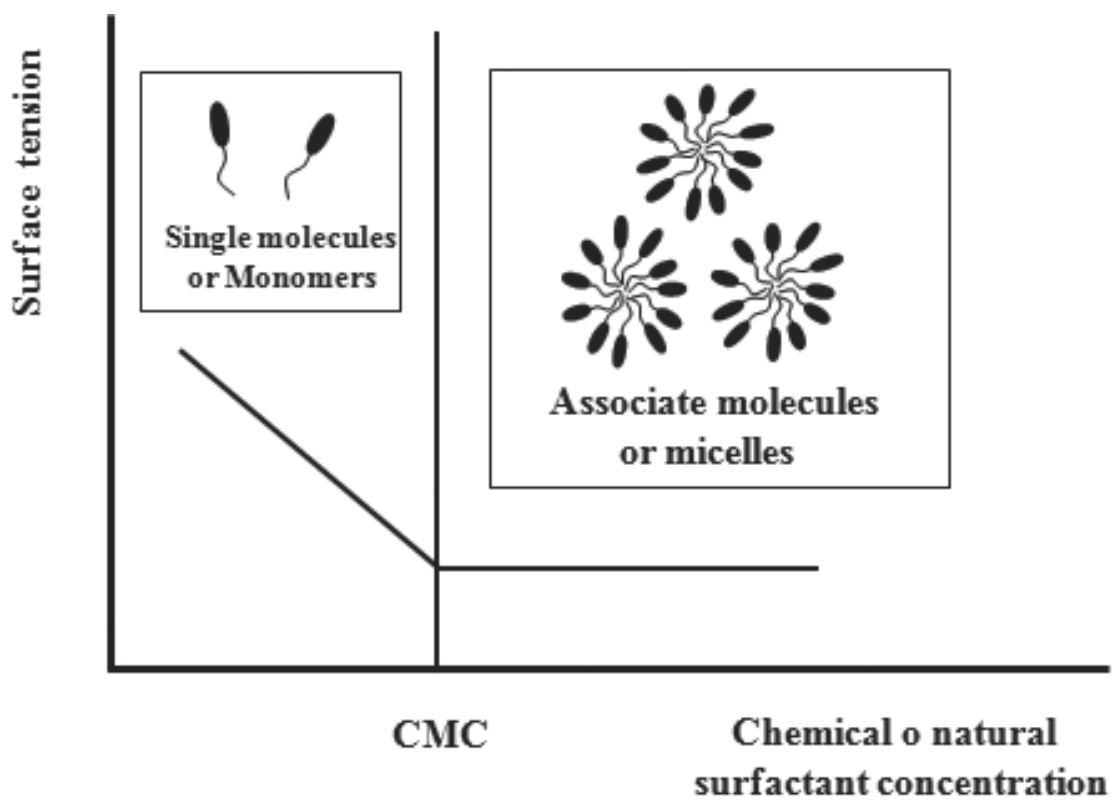

Figure 1. Surface tension as a function of chemical or natural surfactant concentration, CMC represents critical micelle concentration (Patist et al., 2000; Whang et al., 2008).

The HLB number is also an important parameter of the surfactants, describing their physical properties and is specific for each surfactant. This number is determined by the relationship of the hydrophilic and the hydrophobic parts of the surfactant molecule (Tiehm, 1994). This indicates the types of oils that can emulsify them and can be also used to determine their suitability for use. Surfactants with a low HLB are lipophilic where- as a high HLB is indicative of better water solubility (West and Harwell, 1992; Tiehm, 1994). In terms of the hydrophilic portion, surfactants are classified as anionic (negative charge), cationic (positive charge), zwitterionic (both negative and positive charges), or nonionic (no charge) (West and Harwell, 1992; Volkering et al., 1998). Table 1 shows the CMC and HBL number, as well as charge type, of some surfactants. 
Table 1. The charge type, critical micelle concentration (CMC) and hydrophilic-hydrophobic balance number (HLB) of some surfactants, adapted from Doong and Lei (2003).

\begin{tabular}{|c|c|c|c|c|c|}
\hline Surfactant & $\mathbf{M W}^{\dagger}$ & Charge type & CMC & HLB & Reference \\
\hline $\mathrm{SDS}^{\dagger}$ & $288 \mathrm{~g} \mathrm{~mol}^{-1}$ & Anionic & $8.10 \mathrm{mM}$ & 40.0 & Eriksson et al. (2002) \\
\hline Triton X-100 & $628 \mathrm{~g} \mathrm{~mol}^{-1}$ & Nonionic & $0.31 \mathrm{mM}$ & 13.5 & Eriksson et al. (2002) \\
\hline Tween 80 & $1310 \mathrm{~g} \mathrm{~mol}^{-1}$ & Nonionic & $0.01 \mathrm{mM}$ & 15.0 & Eriksson et al. (2002) \\
\hline Brij 35 & $1198 \mathrm{~g} \mathrm{~mol}^{-1}$ & Nonionic & $0.05 \mathrm{mM}$ & 16.9 & $\begin{array}{l}\text { Yeom et al. (1996), Zhu } \\
\text { and Feng (2003) }\end{array}$ \\
\hline Igepal CA-720 & $735 \mathrm{~g} \mathrm{~mol}^{-1}$ & Nonionic & $0.23 \mathrm{mM}$ & 14.6 & $\begin{array}{l}\text { Saichek and Reddy } \\
\text { (2004) }\end{array}$ \\
\hline $\begin{array}{l}\text { Rhamnolipid } \\
\text { JBR515 }\end{array}$ & $577 \mathrm{~g} \mathrm{~mol}^{-1}$ & Anionic & $0.02 \mathrm{mM}$ & $22-24$ & $\begin{array}{l}\text { Xie et al. (2005), } \\
\text { Nguyen et al. (2008) }\end{array}$ \\
\hline Saponin & $1800-2000 \mathrm{Da}$ & Nonionic & $87.60 \mathrm{mg} / \mathrm{L}$ & - & $\begin{array}{l}\text { Soeder et al. (1996), Urum } \\
\text { and Pekdemir (2004), } \\
\text { Rigano et al. (2009) }\end{array}$ \\
\hline Lecithin & $773 \mathrm{~g} \mathrm{~mol}^{-1}$ & Zwiterionic & $610.00 \mathrm{mg} / \mathrm{L}$ & $3-4$ & $\begin{array}{c}\text { Soeder et al. (1996), } \\
\text { Bergenstahl and Fontell (1 } \\
\text { 983), Cubero et al. (2002), } \\
\text { Aulton (2004) }\end{array}$ \\
\hline Tergitol NP-10 & $683 \mathrm{~g} \mathrm{~mol}^{-1}$ & Nonionic & $0.05 \mathrm{mM}$ & 14.0 & $\begin{array}{l}\text { Laha and Luthy (1991), } \\
\text { Mulder et al.(1998) }\end{array}$ \\
\hline
\end{tabular}

$\dagger: \mathrm{MW}=$ Molecular weight; SDS = Sodium dodecyl sulfate

\section{1 Synthetic surfactants}

Surfactants that are produced chemically are known as synthetic surfactants. The hydrophobic chain of these surfactants are paraffins, olefins, alkylbenzenes, alkylphenols and alcohols; the polar group is usually either a sulphate group, a sulphonate group, or a carboxylate group for anionic surfactants, or a quaternary ammonium group for cationic surfactants. For nonionic surfactants the polar groups are poly- oxyethylenes, sucrose, or polypeptides (Volkering et al., 1998). The most common chemical surfactants are sodium dodecyl sulfate (SDS), Triton X-100 (TX100) and Tween 80 (TW80).

Synthetic surfactants are readily available and of (relatively) low cost, so are extensively utilized in remediation processes of contaminated water or soil. On the other hand, the low yields and high costs that can be incurred in the production of biosurfactants (Deleu and Paquot, 2004; Mukherjee et al., 2006; Banat et 
al., 2010) have restricted their use. However, considerable attention has been paid to the production and study of biosurfactants, since they offer several advantages over synthetic surfactants: low toxicity, low $\mathrm{CMC}$, biodegradability, ecological acceptability, high selectivity, and specific activity at extreme temperatures, $\mathrm{pH}$, and salinity (West and Harwell, 1992; Desai and Banat, 1997; Kosaric, 2001; Anandaraj and Thivakaran, 2010).

\section{2 Biosurfactants}

Natural surfactants surfactants or biosurfactants can be produced extracellularly or as part of the cell membrane by a wide variety of microorganisms such as bacteria, fungi, and yeast. Some examples include Pseudomonas aeruginosa (produces rhamnoplids), Bacillus subtilis (produces a lipopeptide called surfactin) (Ron and Rosenberg, 2001; Mata-Sandoval et al., 2002; Mulligan, 2005), Nocardia amarae (Moussa et al., 2006), and Saccharomyces lipolytica CCT0913 (Lima and Alegre, 2009). Most biosurfactants are either anionic or neutral, only a few are cationic, containing amine groups. The hydrophobic part is based on long chain fatty acids, hydroxyl fatty acids or $\alpha$-alkyl- $\beta$-hydroxy fatty acids. The hydrophilic group can be a carbohydrate, amino acid, cyclic peptide, phosphate, carboxylic acid or alcohol (Mulligan et al., 2001).

Biosurfactants are grouped mainly by their chemical composition and their microbial origin. The main classes of these compounds include glycolipids; lipopeptides and lipoproteins; fatty acids, phospholipids, and neutral lipids; and polymeric biosurfactants, as has been reviewed by Desai and Banat (1997), Kosaric (2001), Rahman and Gakpe (2008) and Gautam and Tyagi (2006). Besides, biosurfactants can be classified according to their molecular weight into two main classes, low-molecular-weight molecules called biosurfactants and high-molecular-weight polymers or bioemulsans (Neu, 1996; Rosenberg and Ron, 1999). Biosurfactants lower surface and interfacial tension; this group includes glycolipids, lipopeptides, phospholipids, and proteins. On the other hand, bioemulsans are more effective as emulsion-stabilizing agents, i.e. stabilize oil-in-water; this group includes polymers of polisaccharides, lipoproteins, and particulate surfactants (Neu, 1996; Rosenberg and Ron, 1999; Perfumo et al., 2010). In this context, surfactin and rhamnolipids are low-molecular mass biosurfactants with molecular weight of 1036 and $802 \mathrm{Da}$, respectively (Mulligan and Gibbs, 1990). Besides, emulsan an extracellular lipopolysaccaharide biosurfactant produced by Acinetobacter calcoaceticus, is a high-molecular-weight bioemulsifier with an average molecular weight of about $1000 \mathrm{kDa}$ (Kim et al., 1997). Alasan is another bioemulsifier complex produced by Acinetobacter radioresistens KA53, with an average molecular weight of $1 \mathrm{MDa}$ (Navon-Venezia et al., 1995).

Biosurfactants can be synthesized using different microorganisms and carbon sources and production is influenced by the composition of the medium and by culture conditions (Desai and Banat, 1997; Franzetti et al., 2009). The carbon sources used for biosurfactant production are hydrocarbons, carbohydrates, vegetable oils and oil wastes, olive oil mill effluent, lactic whey and distiller wastes, starchy substrates, renewable resources, industrial and/ or municipal wastewater, under aerobic conditions (Kosaric, 1992; Desai and Banat, 1997; Gautam and Tyagi, 2006). In this context, Franzetti et al. (2008) found three new bacterial strains hydrocarbon-degrading Gordonia genus. They were isolated from a site chronically contaminated by diesel. These strains were able to grown using a wide range of straight and branched aliphatic hydrocarbons as carbon and energy sources and to produce at least two classes of 
surface-active compounds, emulsifying agents and water-soluble substrates. Cell-bound biosurfactants, which reduce surface tension, were produced in hydrocarbons; however their production was lower in water soluble substrates. Gordonia sp. BS29 synthesized, and then released extracellularly, bioemulsions during the exponential phase with $n$-hexadecane as carbon and energy source. The production of biosurfactants started in the exponential phase and their concentration increased following linear growth. Calvo et al. (2008) isolated Ochrobactrum anthropi strain $\mathrm{AD} 2$ from the waste water treatment plant of an oil refinery. This bacterium produced exopolysaccharide AD2 (exopolysaccharide emulsifiers) in glucose nutrient broth media with various added hydrocarbons; such as n-octane, mineral light and heavy oils and crude oils. In addition, Franzetti et al. (2009) studied the cultural factors that affecting the production of the cell-bound biosurfactants by Gordonia sp. BS29. Their research evaluated the type and concentration of the carbon source, the concentration of phosphates and sodium chloride, and the interactions among these factors. The results showed that with the optimized cultural conditions a 5-fold increase in the biosurfactant concentration, compared to the un-optimized medium, was obtained. The optimization did not change the number and type of the glycolipid biosurfactants produced by Gordonia sp. BS29.

The phytogenic surfactant is another group of biosurfactants, such as saponins and lecithins (Soeder et al., 1996), and humic acids (Conte et al., 2005). The phytogenic surfactants are released from decaying roots, and can be found in considerable amounts in the rhizosphere, where phosphatidylcholine, the most important component of lecithin, is the major phospholipid (Soeder et al., 1996).

Cyclodextrins are another group of substances that enhanced the apparent solubility and biodegradation of hydrophobic organic compounds (HOCs) in aqueous solutions and contaminated soil (Boyle, 2006). These substances can imitate the function of surfactants since they can form soluble complexes with hydrophobic compounds. Cyclodextrins have a non-polar cavity into which the HOCs partition to form inclusion complexes and a polar exterior that provides the molecule with a relatively high aqueous solubility. Moreover they are of interest in microbial processes because they do not exhibit the toxicity of many synthetic surfactants (Singh et al., 2007).

The most important characteristic of biosurfactants is their environmental acceptability, as they are biodegradable, have lower toxicity than synthetic surfactants, their own specific action, effectiveness at extremes of temperature, $\mathrm{pH}$ and salinity, and are ecologically safe, as it has been reviewed by Kosaric (1992) and Desai and Banat (1997). These properties have allowed use of biosurfactants in the remediation of inorganic compounds such as heavy metals (Kosaric, 1992; Zouboulis et al., 2003), and in the remediation of organic compounds such as hydrocarbons (Franzetti et al., 2008). Also, the ability to reduce the interfacial tension of oil in water has allowed applied of biosurfactants for the removal of water from emulsions prior to processing (Mulligan, 2005) and therefore they are applied in oil recovery (Plaza et al., 2008; Abdolhamid et al., 2009). Moreover, natural surfactants have been used in the food processing industry, and the health care and cosmetics industries (Desai and Banat, 1997). The properties of biosurfactants have generated a large number of investigations, which have allowed identification of new microorganism producers of natural surfactants, determination of their structure, finding new sources of carbon and energy, enhancing the production processes, and generating several patents (Shete et al., 2006). 


\section{Influence of biosurfactants on the bioavailability of hydrophobic organic compounds}

The bioavailability of HOCs can be enhanced by biosurfactants through the following mechanisms: emulsification of non-aqueous phase liquid contaminants (Edwards et al., 1991; Volkering et al., 1998; Jiménez Islas et al., 2010), enhancement of the apparent solubility of the pollutants (Edwards et al., 1991; Volkering et al., 1995), and facilitated transport of the pollutants from the solid phase (Yeom et al., 1996; Jiménez Islas et al., 2010). These mechanisms may cause enhanced mass transport and their relative contributions strongly depend on the physical state of the pollutants (Volkering et al. 1998). A fourth possible mechanism has been suggested by Tang et al., (1998) and Poeton et al. (1999): the biosurfactants help microorganisms adsorb to soil particles occupied by the contaminant, thus decreasing the diffusion path length between the sites of adsorption and the site of biouptake by the microorganisms.

In the first mechanism, emulsification of non-aqueous phase liquid contaminants, the biosurfactants can decrease the interfacial tension between and aqueous and non-aqueous phase. This may guide the formation of micro and macro emulsions. This results in an increase in the contact area, enabling improved mass transport of the contaminants to the aqueous phase and in mobilization of sorbed liquid-phase contaminants (Edwards et al., 1991, Volkering et al., 1998).

The second mechanism, enhancement of the apparent solubility of the HOCs, is due to presence of micelles that contain high concentrations of HOCs in the hydrophobic center of the micelles (Edwards et al., 1991, Volkering et al., 1995). Brown (2007) explains the apparent aqueous solubility of the contaminant as the sum of the aqueous $\left(\mathrm{C}_{\mathrm{aq}}\right)$ and micellar $\left(\mathrm{C}_{\text {mic }}\right) \mathrm{HOC}$ concentrations. Edwards et al., (1991) established that micellar-phase HOC concentration can be modeled using a linear partition relationship of the form:

$$
\mathrm{C}_{\text {mic }}=\mathrm{k}_{\text {mic }} \mathrm{C}_{\text {mic }} \mathrm{C}_{\mathrm{aq}}
$$

where $\mathrm{k}_{\text {mic }}$ is the HOC-micelle partition coefficient and $\mathrm{S}_{\text {mic }}$ is the micelle concentration. The $\mathrm{S}_{\text {mic }}$ correspond to difference between the total surfactant concentration and their $\mathrm{CMC}$.

Finally, facilitated transport of the contaminants from the solid phase can involve several processes, such as the interaction of contaminants with single biosurfactant molecules, the interaction of surfactants with separate-phase or sorbed hydrocarbons, the mobilization of contaminants by swelling of the organic matrix, and the mobilization of contaminants trapped in soil caused by lowering of the surface tension of the soil particle pore water in soil particles, as it has been reviewed by Volkering et al. (1998).

The use of biosurfactants can improve the bioremediation processes by mobilization, solubilization or emulsification (Urum and Pekdemir, 2004; Nguyen et al. 2008). The mobilization and solubilization mechanisms are promoted low-molar mass biosurfactants, at below and above the $\mathrm{CMC}$, respectively. Whereas, the emulsification processes is promoted by highmolar mass biosurfactant (Urum and Pekdemir, 2004; Pacwa-Plociniczak et al., 2011).

\subsection{Emulsification and solubilization of hydrophobic organic contaminants by biosurfactants}

Whang et al. (2008) studied the capacity of rhamnolipid and surfactin to reduce surface tension. The biosurfactants were produced by $P$. aeruginosa $\mathrm{J} 4$ and $B$. subtilis ATCC 21332, respectively. The results showed that the biosurfactants were able to reduce surface 
tension to less than 30 from 72 dynes $\mathrm{cm}^{-1}$ with $\mathrm{CMC}$ values of 45 and $50 \mathrm{mg} \mathrm{L}^{-1}$ for surfactin and rhamnolipid, respectively. Also, the results of diesel dissolution experiments demonstrated that the diesel solubility was enhanced with increased biosurfactant addition.

Most studies of the effect of surfactants on the solubilization of PAHs have been performed under mesophilic conditions. Related to this, Wong et al. (2004) evaluated the influence of TW80, TX100 and the biosurfactants produced from $P$. aeruginosa strain P-CG3 and P. aeruginosa strain ATCC 9027 on the solubilization of phenanthrene under thermophilic conditions. They found that the surfactants enhanced the solubility of phenanthrene at $50^{\circ} \mathrm{C}$. The biosurfactant from P-CG3 was the most effective with a 28-fold increase in apparent solubility of phenanthrene at a concentration of $10 \mathrm{x} \mathrm{CMC}$, compared with the controls (TW80 and TX100).

Franzetti et al. (2009) determined that the BS29 bioemulsans, produced by Gordania sp. strain BS29, effectively remove crude oil and PAHs from soil. The crude oil removal by BS29 bioemulsans is comparable with rhamnolipid in the same experimental conditions.

Barkay et al. (1999) evaluated the effect of alasan in the enhancement of solubilization of polycyclic aromatic hydrocarbons (PAHs). Alasan is a high-molecular-weight bioemulsifier complex of an anionic polysaccharide and proteins. The concentration of solubilized PAHs increased linearly with the addition of the biosurfactant ( 50 to $500 \mu \mathrm{g} \mathrm{mL}^{-1}$ ). The apparent aqueous solubilities of PAHs were increased higher than their solubilities without alasan. The results of physicochemical characterization of the solubilization activity suggest that alasan solubilizes PAHs by physical interaction, likely of the hydrophobic nature, and that this interaction is slowly reversible. Moreover, the increase in apparent aqueous solubility of PAHs does not depend on the conformation of alasan and is not affected by the formation of multimolecular ag- gregates of alasan above its saturation concentration. Also, alasan enhances the biodegradation of PAHs.

Tecon and van der Meer (2010) evaluated the effects of two types of biosurfactants produced by Pseudomonas sp. (cyclic lipopeptides and rhamnolipids) on phenanthrene bioavailability. They measured the bioavailability from growth rates on contaminants and from specific induction of a phenanthreneresponsive green fluorescent protein (GFP) reporter in Burkholderia sartisoli strain RP037. Their results showed that the co-culturing of strain RP037 with lipopeptide-producing bacterium Pseudomonas putida strain PCL1445 enhanced GFP expression, compared to a single culture, but this effect was not significantly different when strain RP037 was co-cultivated with a non-lipopeptide-producing mutant of $P$. putida. The addition of partially purified supernatant extracts from the $P$. putida lipopeptide producer also did not unequivocally enhance phenanthrene bioavailability for strain RP037, compared to controls. In contrast, a $0.1 \%$ rhamnolipid solution strongly augmented RP037 growth rates on contaminants and led to a significantly larger proportion of cells in culture with high GFP expression.

\subsection{Desorption of hydrophobic organic compounds by biosurfactants}

The HOCs in contact with the soil are associated with organic matter by different mechanisms: adsorption and electrostatic and covalent bonding (Alexander, 1995). Adsorption is the most important mode of interaction between soil and HOCs. Adsorption processes of these pollutants in soil occur from complete reversibility to total irreversibility. Prolonged exposure time to the pollutant decreases its bioavailability. The extent of adsorption depends on the properties of the soil (mineral and organic matter content) and of the contaminant (solubility, polarity, molecular structure), as 
has been reviewed by Semple et al. (2003) and Gevao et al. (2000). Hence, the application of biosurfactant solutions, in soil-water systems, may result in the transfer of HOCs from the soil-sorbed phase to the aqueous phase, allowing mass-transfer processes and biodegradation (Aronstein et al., 1991; Tiehm, 1994; Volkering et al., 1995; Jiménez Islas et al., 2010).

Biosurfactants can be effective in facilitating desorption of the pollutants from soil as a possible integral part of a biodegradation process (Mata-Sandoval et al., 2002) or in an aqueous soil washing method, where a biological or nonbiological process is subsequently applied to remove the contaminants from the recovered aqueous washing (Singh et al., 2007). Bioemulsifiers from bacterias were able to emulsify n-octane, toluene, xylene, mineral oil and crude oil and they looked promising for remediation application (Toledo et al., 2008). Urum and Pekdemir (2004) evaluated the ability of aqueous biosurfactant solutions for possible applications in washing crude oil contaminated soil. The results showed that the biosurfactants were able to remove significant amounts of crude oil from contaminated soil. Rhamnolipid removed up to $80 \%$ oil and lecithin about $42 \%$. In comparison with distilled water washing, crude oil removal from soil using aescin (mixture of saponins), lecithin, saponin and tannin was not effective. These investigators propose that the removal was due to mobilization, caused by the reduction of surface and interfacial tensions. On the other hand, Kang et al. (2010) investigated the effectiveness of sophorolipid in washing and biodegradation of hydrocarbons and crude oil in soil on a laboratory scale. The results showed that the addition of this biosurfactant to soil enhanced the washing and the biodegradation of the tested hydrocarbons.

Another important aspect to consider is the sorption of biosurfactants onto soil, a condition that can cause natural surfactant losses, which in turn reduce the performance of the solubilization of hydrophobic contaminants (Chu, 2003; Zhou and Zhu, 2007), decrease the remediation efficiency and result in an increase in remediation time and costs (Yu et al., 2007; Zhou and Zhu, 2008). At biosurfactant concentrations below the $\mathrm{CMC}$, competitive adsorption of an organic compound by soil and by a biosurfactant in solution may occur, which may cause an increase or a decrease in the desorption of the contaminant from soil, depending on the characteristics of the soil and the organic compound, as has been reviewed by Rodríguez-Cruz et al. (2004). Pei et al. (2009) examined the effect of biosurfactant on the sorption of phenanthrene onto the original or $\mathrm{H}_{2} \mathrm{O}_{2}$-treated black loamy soil and red sandy soil. The result showed that organic matter played an important role in phenanthrene sorption onto the soil evaluated. The changes values of partition coefficient suggested that biosurfactant inhibited phenanthrene sorption onto the black loamy soil, however facilitated phenanthrene, sorption onto the red sandy soil. On the other hand, was observed that biosurfactant could also be sorbed onto soils. The maximal sorption capacity of the red sandy soil was $76.9 \mu \mathrm{g} \mathrm{g}^{-1}$, which was 1.31 times that of black loamy soil. Moreover, biosurfactant was degraded in the two selected soils, and $92 \%$ was mineralized after 7 days of incubation. It implied that biosurfactant should be added frequently in remediation process of PAHcontaminated soils. The research of Van Dyke et al. (1993). showed that the ability of UG2 rhamnolipid, produced by $P$. aeruginosa UG2, to enhance removal of PAHs into the aqueous phase was affected by the soil type, hydrocarbon equilibration time, and biosurfactant adsorption to soil.

\subsection{Influence of biosurfactants on the desorption and solubilization of aged chemicals in soil}

Organic compounds freshly added to soils are bound almost exclusively to the soil particle surfaces (ad- 
sorption) and their desorption is almost complete after a short period of time (Hatzinger and Alexander, 1995; Alexander, 2000). However, if the time of contact between a pollutant and soil increases, decrease in chemical and biological availability occurs, called "ageing" or "sequestration" (Alexander, 1995; Hatzinger and Alexander, 1995; Semple et al., 2003). In the process of ageing, the interactions between soil and HOCs are affected by: the soil organic matter, both its amount and its nature; inorganic components with particular consideration to pore size and structure; microbial activity; and pollutant concentration, as it has been reviewed by Semple et al. (2003).

Over the past few years, numerous researchers have studied the biosurfactant-enhanced desorption of organic contaminants adsorbed onto soil. However, few works reported in the literature have addressed the influence of the time of residence in the soil, or ageing time, of organic pollutants on their desorption in soil-water-surfactant systems. Fava et al. (2004) evaluated the effects of soya lecithin on the desorption of PAHs in an aged-contaminated soil and they obtained a faster and more extensive overall removal of PAHs accompanied by a large soil detoxification under slurry-phase conditions. After 150 days of incubation at room temperature, about $60 \%$ of the original PAHs was biodegraded. Berselli et al. (2004) investigated the effects of TX100 and the biogenic agents: cyclodextrins, humic substances, and rhamnolipids, on the washing of a soil historically contaminated with PAHs. The soil was washed in water with $1 \%$ of biogenic agents or TX100 and both the biogenic agents and the synthetic surfactant enhanced the capacity of water to elute organic contaminants from the soil. The biogenic agents sustained the biodegradation of contaminants by enhancing the availability to bacteria; in contrast,
TX100 affected the bioremediation due to their toxic effects on bacterial biomass.

The results of Leonardi et al. (2007) showed that the addition of several surfactants (soybean oil, Tween 20, TW80 and olive-mill wastewater) to an aged soil with a negligible amount of the non-bioavailable fraction of PAHs had either a limited or even a negative impact on PAH degradation by Irpex lacteus and Pleurotus ostreatus.

Fava et al. (2003) studied the effects of methyl$\beta$-cyclodextrins on the solubilization of polychlorinated biphenyls (PCB) of two different real, aged contaminated soils in bench-scale reactors. They found that the addition of 0.5 and $0.1 \%$ of methyl- $\beta$ cyclodextrins increased the concentration of PCBs in the water phase in slurry-phase reactors.

In general, most pesticides used in agriculture are moderately hydrophobic compounds, with complex molecular structures that differ from hydrocarbons in their lower hydrophobicity and in the presence of a polar functional group. These compounds are also strongly adsorbed by soil organic matter and desorption is limited (Rodríguez-Cruz et al., 2004). Their desorption rate decreased with an increase in ageing time. Wattanaphon et al. (2008) evaluated the ability of a BS biosurfactant produced by Burkholderia cenocepacia BSP3 to enhance pesticide solubilization for further application in environmental remediation. The BS biosurfactant was identified as a glucolipid, having a CMC of $316 \mathrm{mg} \mathrm{L}^{-1}$. Moreover, it lowered the surface tension of deionized water to $25 \pm 0.2 \mathrm{mN} \mathrm{m}^{-1}$ and exhibited good emulsion stability. The results showed that the application of the BS biosurfactant to facilitate pesticide solubilization demonstrated that this biosurfactant at concentrations below and above its CMC could enhance the apparent water solubility of methyl parathion, ethyl parathion and trifluralin. 


\section{Influence of biosurfactants on the degradation of hydrophobic organic contaminants by microorganisms}

\subsection{Biosurfactant-microorganism interactions}

Biosurfactants have the potential to enhance the bioavailability of HOCs in contaminated sites, and therefore enhance the efficiency biodegradation processes. In general, the biosurfactants are considered as low or non-toxic (Desai and Banat, 1997). Soeder et al. (1996) showed that the soya lecithin had a lower bacterial toxicity than quillaya saponin. Flasz et al. (1998) determined that the synthetic surfactants presented higher toxicity and mutagenic effect, whereas that the natural surfactants were considered slightly non-toxic and non-mutagenic. Boyle (2006) evaluated the effects of various cyclodextrins (Gamma W8, Beta W7 M1.8 and Alpha W6 M1.8) and pentachlorophenol on the radial growth of the white-rot fungus Trametes hirsute. The results at $\mathrm{pH} 4.9$ showed that the cyclodextrin Gamma W8 eliminated the inhibitory effects of $10 \mathrm{mg} \mathrm{L}^{-1}$ of pentachlorophenol and partially overcame those at $50 \mathrm{mg} \mathrm{L}^{-1}$. Beta W7 M1.8 also alleviated inhibition, but the effect was less pronounced and Alpha W6 M1.8 had little effect. In control assays, without pentachlorophenol, cyclodextrins did not affect radial growth of $T$. hirsute. On the other hand, Bustamante et al. (2011) found that the increase in soya lecithin concentration from 0 to $10 \mathrm{~g} \mathrm{~L}^{-1}$ caused an increase in mycelia growth of Anthracophyllum discolor, a white-rot fungus isolated from a Chilean forest. However, biosurfactants can be exerting negative effects on the biodegrading microorganisms (Fava and Di Gioia, 2001), bacteria, fungi, algae, and virus, as it has been by Volkering et al. (1995), Muthusamy et al. (2008), and Banat et al. (2010). Some biosurfactants have antibiotic prop- erties, which can inhibit spore germination, hyphal growth of some fungi. Das et al. (2008) showed that a biosurfactant from Bacilus circulans, different from surfactin produced from $B$. subtilis, was effective for Gram-negative and Gram-positive pathogenic and semipathogenic microorganisms. In the medical, cosmetics, and pharmaceutical areas, biosurfactant have been used to inhibit bacterial growth, cell lysis, tumor growth, synthesis of cell wall, and to stimulate enzymes, inhibit the adhesion of pathogenic organisms to solid surfaces and the recovery of purified intracellular proteins. More applications are reviewed in the articles published by Muthusamy et al. (2008) and Gharaei-Fathabad (2011). The effect of biosurfactants on the microorganisms will depended of factors, such as: biosurfactant concentration and bioavailability, environmental and cultural conditions, charge type of biosurfactants, and characteristic and properties of microorganisms as cellular ultraestructure (Van Hamme et al., 2006).

\subsection{Effect of biosurfactants on the degradation of hydrophobic organic pollutants by white-rot fungi}

Most of the studies have been directed towards removal of HOCs from soil using biosurfactants and added bacteria or indigenous soil microorganisms; but few studies have addressed the removal of hydrophobic pollutants from soil using biosurfactants and whiterot fungi, which indicates the necessity of evaluating the potential ligninolytic effect of this combination.

White-rot fungi have the ability to degrade a wide range of persistent or toxic environmental contaminants, such as PCBs, PAHs, pentachlorophenol, pesticides, dioxins, and synthetic dyes, among others, which makes them good candidates for use in processes of bioremediation (Barr and Aust, 1994; Pointing, 2001; Eichlerová et al., 2005; Tortella et al., 2005; Ru- 
bilar et al., 2008; Rubilar et al., 2011). The potential of white-rot fungi resides in their enzymatic system, which is nonspecific, and secreted into the extracellular environment (Durán and Esposito, 2000). White-rot fungi secrete one or more of the three enzymes that are essential for the degradation of lignin: laccase (Lac), lignin peroxidase (LiP), and Mn dependant peroxidase (MnP) (Reddy, 1995; Pointing, 2001; Eichlerová et al., 2005). These enzymes are secreted during secondary metabolism, as a result of nutrient depletion of carbon or sulphur, or especially, manganese and nitrogen (Hamman et al., 1997; Leung and Pointing, 2002). Other factors are also implicated, such as initial $\mathrm{pH}$ of the medium and incubation temperature (Bustamante et al., 2011), the level of aeration and agitation during incubation, the availability of mediator compounds and metals (Leung and Pointing, 2002; Mouso et al., 2003; Cordi et al., 2007), or the presence and concentration of surfactants (Rodríguez Couto et al., 2000; Ürek and Pazarlioğlu, 2005; Wang et al., 2008). Recently, Bustamante et al. (2011) determined that $A$. discolor produced more activity of $\mathrm{MnP}$ when soya lecithin was included in the growth medium. Yamanaka et al. (2008) found that supplementation of a Trametes villosa culture medium with a vegetable oil-surfactant emulsion induced $\mathrm{MnP}$ activity and higher Lac activity when copper was added. On the other hand, Zhou et al. (2007) showed that white-rot fungi degraded decabromodiphenyl ether (BDE-2009, a widely used flame retardant) and that TW80 and b-cyclodextrin could both increase the biodegradation.

\section{Remediation applications}

The addition of biosurfactants, bioemulsifiers, and/or biosurfactant-producing microorganisms can be used in soil biodegradation techniques, soil washing, and water and waste treatment (in situ and ex situ) (Urum and Pekdemir, 2004; Zhou and Zhu, 2008). Biosur- factants have also been found to be useful for oil spill remediation and for dispersing oil slicks into fine droplets and converting mousse oil into an oil-in-water emulsion (Toledo et al., 2008).

Barkay et al. (1999) examined the influence of the bioemulsifier alasan on the biodegradation fates of PAHs. The presence of alasan $\left(500 \mu \mathrm{g} \mathrm{mL}^{-1}\right)$ more than doubled the rate of $\left[{ }^{14} \mathrm{C}\right]$ fluoranthene mineralization and significantly increased the rate of $\left[{ }^{14} \mathrm{C}\right]$ phenanthrene mineralization by Sphingomonas paucimobilis EPA505. Shin et al. (2006) used a rhamnolipid from Pseudomonas to remediate soil contaminated with phenanthrene by the combined solubilizationbiodegradation process. They reported a high percentage of removal in the solubilization step and a significant decrease of phenanthrene in the soil sample during the biodegradation. From their results, they suggest that the degradation of contaminants by specific species might not be affected by the residual biosurfactants following application of the solubilization process that they would not present negative effects to the environment, and that they could be combined with the biodegradation process to improve the removal efficiency.

Soeder et al. (1996) studied the influence of two phytogenic surfactants, quillaya saponin and soya lecithin, on the biodegradation of PAHs. They found that high concentrations of phytogenic surfactants efficiently solubilized phenanthrene and fluoranthene. On the other hand, Fava and Di Gioia (2001) evaluated the effects of soya lecithin on the bioremediation of PCBs in an artificially contaminated soil and, in this work; the soya lecithin enhanced the availability of PCBs, while soya lecithin was also found to be an excellent carbon source for the microorganisms. Similar results were obtained by Fava et al. (2004) when studying the influence of soya lecithin on the bioremediation of an aged-PAHs contaminated soil. These results suggest the capacity of a pythogenic surfactant, soya lecithin, 
to improve the bioavailability of HOCs in contaminated sites. In addition, they have other properties, such as being nontoxic and biodegradable.

The bioremediation of petroleum is carried out by microorganisms capable of utilizing hydrocarbons as a source of energy and carbon. These microorganisms are ubiquitous in nature and are capable of degrading various types of hydrocarbons, all with low solubility in water. The hydrocarbon-degrading microorganisms generally produce emulsifiers, so biosurfactants help to disperse the oil, increase the surface area for growth, remove the bacteria from the oil droplets after the utilizable hydrocarbon has been depleted (Ron and Rosenberg, 2002), and stimulate the indigenous bacterial population to degrade hydrocarbons at rates higher than those which could be achieved through addition of nutrients alone (Desai and Banat, 1997). Whang et al. (2008) investigated the application of a biosurfactant, rhamnolipid and surfactin, for enhanced biodegradation of dieselcontaminated water and soil. Their results in diesel/ water batch experiments showed that with the addition of $40 \mathrm{mg} \mathrm{L}^{-1}$ of surfactin, there was significantly enhanced biomass growth as well as increased diesel biodegradation (94\%), compared with $40 \%$ in batch experiments without surfactin. A concentration of biosurfactant more than $40 \mathrm{mg} \mathrm{L}^{-1}$ decreased both biomass growth and diesel biodegradation. Addition of rhamnolipid to the diesel-water systems from 0 to $80 \mathrm{mg} \mathrm{L}^{-1}$ increased biomass growth and diesel biodegradation. The application of surfactin and rhamnolipid stimulated the indigenous microorganisms for enhanced biodegradation of diesel-contaminated soil. On the other hand, Ralstonia picketti and Alcaligenes piechaudii, which are producers of biosurfactants, degraded crude oil over $80 \%$ in 20 days incubation (Plaza et al., 2008).

Exopolysaccharide AD2 (EPS emulsifier) produced by $O$. anthropi strain $\mathrm{AD} 2$ was tested in soil micro- cosms and experimental biopiles. Also, its efficiency in mixtures with activated sludge from an oil refinery was tested. In soil microcosms the EPS emulsifier together with an oleophilic fertilizer (S200 C) increased the indigenous microbial populations as well as hydrocarbon degradation and therefore decreased the amount of hydrocarbon remaining. Similar effects were obtained in biopile assays amended with EPS emulsifier plus activated sludge (Calvo et al., 2008).

In soil washing, the recovery and reuse of biosurfactants would be the preferred option because of the expense involved in production, although, if they are labile, this may not be an option (Christofi and Ivshina, 2002). Rhamnolipids have been proposed as soil washing agents for an enhanced removal of organic pollutants and metals from soil. A potential limitation to the application of biosurfactants is sorption by soil matrix components. Pseudomonas spp. produce rhamnolipids, either in the monorhamnolipid form or, more frequently, as a mixture of the mono- and dirhamnolipid forms. Ochoa-Loza et al. (2007) demonstrated that monorhamnolipid sorption on soil matrix components is concentration-dependent, and that the monorhamnolipid form sorbs more strongly alone than when in a mixture of forms. Conte et al. (2005) compared the efficiency of a humic acid with that of common surfactants, SDS and TX100, and water in the washing of polluted soil in the contaminated industrial area of a chemical plant. The results showed that the water was unable to fully remove pollutants from the soil, whereas all the organic surfactants revealed similar efficiencies (up to 90\%) in the removal of the pollutants from the soils. Hence, the use of solutions of natural humic acids appears to be a better choice for soil washings of highly contaminated soils due to their additional capacity to promote microbial activity, in contrast to chemical surfactants.

Biosurfactants may have applications in metal treatment (Soeder et al., 1996; Zouboulis et al., 2003; 
Aşçi et al., 2007). Heavy metals along with other metals and minerals have been released from their natural chemical compounds through industrial activities and processes into rivers, lakes and other surface waters. Since the sediments that have become contaminated below these surface waters have large quantities of water after dredging, dewatering is necessary before using treatment techniques (Dahrazma and Mulligan, 2007). Rhamnolipids, due to their anionic nature, are able to remove metals from soil and ions such as cadmium, copper, lanthanum, lead and zinc due to their complexation ability (Mulligan, 2005). Dahrazma and Mulligan (2007) demonstrated that rhamnolipids have the capacity to remove heavy metals from sediments; the removal was up to $37 \%$ of $\mathrm{Cu}, 13 \%$ of $\mathrm{Zn}$, and $27 \%$ of $\mathrm{Ni}$, when the biosurfactant was applied in a continuous flow configuration. Rhamnolipids also presented the capacity for enhanced recovery of $\mathrm{Cd}$ (II) from kaolin, a soil component (Aşçi et al., 2007).

\section{Future prospects}

The continuous release of contaminants, organic and inorganic, through either natural or industrial processes, has led to the accumulation and contamination of soils and sediments, surface and groundwater. Several strategies have been studied and developed to decontaminate and restore these sites. However, the efficiency of these processes is limited principally due to low aqueous solubility of contaminants and, therefore, low availability to both physical-chemical processes and microorganism degraders.

The use of biosurfactants is presented as an attractive option because of its versatility, biodegradability, ecological safety and environmental acceptance. However, their high production cost limits their use in bioremediation processes. In this context, it is necessary to evaluate the culturing conditions that optimize their production, assess the economic use of new substrates, such as those arising from industrial waste, and to evaluate techniques of isolation and purification to make production more economically feasible.

The available information is related to studies under laboratory conditions, and little work has been done on a field scale. Therefore, more efforts are required to evaluate biosurfactant production in situ and their effect on the indigenous microorganisms, and to evaluate the efficiency and effectiveness of a bioremediation processes in situ.

\section{Acknowledgments}

The authors acknowledge FONDECYT 1090678, DIUFRO DI10-TD01, and Convenio de Desempeño Evoluciona-MECESUP for financial support.

\section{References}

Abdolhamid, H.R., Sadiq Al-Baghdadi, M.A.R., El Hinshiri, A.K. 2009. Evaluation of bio-surfactants enhancement on bioremediation process efficiency for crude oil at oilfield: Strategic study. Ovidus University Annals of Chemistry. 20, 25-30.

Alexander, M. 2000. Aging, bioavailability, and over stimulation of risk from environmental pollutants. Environ. Sci. Technol. 34, 4259-4265.

Alexander, M. 1995. How toxic are toxic chemicals in soil?. Environ. Sci. Technol. 29, 2713-2717.

Anandaraj, B., Thivakaran, P. 2010. Isolation and production of biosurfactant producing organism from oil spilled soil. J. Biosci. Tech. 1, 120-126.

Aronstein, B.N., Calvillo, Y.M., Alexander, M. 1991. Effect of surfactant at low concentrations on the desorption and biodegradation of sorbed aromatic compounds in soil. Environ. Sci. Technol. 25, 1728-1731.

Aşçi, Y., Nurbaş, M., Sağ Açikel, Y. 2007. Sorption of $\mathrm{Cd}(\mathrm{II})$ onto kaolin as a soil component and desorp- 
tion of $\mathrm{Cd}(\mathrm{II})$ from kaolin using rhamnolipid biosurfactant. J. Hazard. Mater. B139, 50-56.

Aulton, M.E. 2004. Farmacia, La ciencia del diseño de las formas farmacéuticas. Elsevier España, S. A., Madrid, 87.

Banat, I.M., Franzetti, A., Gangolfi, I., Bestetti, G., Martinotti, M.G., Fracchia, L., Smyth, T.J., Marchant, R. 2010. Microbial biosurfactants production, applications and future potential. Appl. Microbiol. Biotechnol. 87, 427-444.

Barkay, T., Navon-Venezia, S., Ron, E.Z., Rosenberg, E. 1999. Enhancement of solubilization and biodegradation of polyaromatic hydrocarbons by the bioemulsifier alasan. Appl. Environ. Microbiol. 65, 2697-2702.

Barr, D.P., Aust, S.D. 1994. Mechanisms white rot fungi use to degrade pollutants. Environ. Sci. Technol. 28, 78A-87A.

Bergenstahl, B.A., Fontell, K. 1983. Phase equilibria in the system soybean lecithin/water. Prog. Colloid Polym. Sci. 68, 48-52.

Berselli, S., Milone, G., Canepa, P., Di Gioia, D., Fava, F. 2004. Effects of cyclodextrins, humic substances, and rhamnolipis on the washing of a historically contaminated soil and on the aerobic bioremediation of the resulting effluents. Biotechnol. Bioeng. 88, 111-120.

Bollag, J.M., Bollag, W.B. 1995. Soil contamination and the feasibility of biological remediation. Bioremediation: Science and Applications, SSSA Special Publication. 43, 1-10.

Boyle, D. 2006. Effects of $\mathrm{pH}$ and cyclodextrins on pentachlorophenol degradation (mineralization) by white-rot fungi. J. Environ. Manag. 80, 380-386.

Brown, D.G. 2007. Relationship between micellar and hemi-micellar processes and the bioavailability of surfactant-solubilized hydrophobic organic compounds. Environ. Sci. Technol. 41, 1194-1199.
Bustamante, M., González, M.E., Cartes, A., Diez, M.C. 2011. Effect of soya lecithin on the enzymatic system of the white-rot fungus Anthracophyllum discolor. J. Ind. Microbiol. Biotechnol. 38, 189-197.

Calvo, C., Silva-Castro, G.A., Uad, I., García Fandiño, C., Laguna, J., González-López, J. 2008. Efficiency of the EPS emulsifier produced by Ochrobactrum anthropi in different hydrocarbon bioremediation assays. J. Ind. Microbiol. Biotechnol. 35, 1493-1501.

Christofi, N., Ivshina, I.B. 2002. A Review Microbial surfactants and their use in field studies of soil remediation. J. Appl. Microbiol. 93, 915-929.

Chu, W. 2003. Remediation of contaminated soils by surfactant-aided soil washing. Pract. Period. Hazard. Toxic Radioact. Waste Manage. 7, 19-24.

Conte, P., Agretto, A., Spaccini, R., Piccolo, A. 2005. Soil remediation: humic acids as natural surfactants in the washings of highly contaminated soils. Environ. Pollut. 135, 515-522.

Cordi, L., Minussi, R.C., Freire, R.S., Durán, N. 2007. Fungal laccase: copper induction, semi-purification, immobilization, phenolic effluent treatment and electrochemical measurement. Afr. J. Biotechnol. 6, 1255-1259.

Cubero, N., Monferrer, A., Villalta, J. 2002. Colección Tecnología de alimentos. Aditivos alimentarios. Ediciones Mundi-Prensa, Madrid, 169.

Dahrazma, B., Mulligan, C.N. 2007. Investigation of the removal of heavy metals from sediments using rhamnolipid in a continuous flow configuration. Chemosphere. 69, 705-711.

Das, P., Mukherjee, S., Sen, R. 2008. Antimicrobial potential of a lipopeptide biosurfactant derived from a marine Bacillus circulans. J. Appl. Microbiol. 104, 1675-1684. 
Deleu, M., Paquot, M. 2004. From renewable vegetables resources to microorganisms: new trends in surfactants. C. R. Chimie. 7, 641-646.

Desai, J.D., Banat, I.M. 1997. Microbial production of surfactants and their commercial potential. Microbiol. Mol. Biol. Rev. 61, 47-64.

Doong, R.A., Lei, W.G. 2003. Solubilization and mineralization of polycyclic aromatic hydrocarbons by Pseudomonas putida in the presence of surfactant. J. Hazard. Mater. B96, 15-27.

Durán, N., Esposito, E. 2000. Potential applications of oxidative enzymes and phenoloxidase-like compounds in wastewater and soil treatment: a review. Appl. Catal. B: Environ. 28, 83-99.

Edwards, D.A., Luthy, R.G., Liu, Z. 1991. Solubilization of polycyclic aromatic hydrocarbons in micellar nonionic surfactant solutions. Environ. Sci. Technol. 25, 127-133.

Eichlerová, I., Homolka, L., Lisá, L., Nerud, F. 2005. Orange $\mathrm{G}$ and Remazol Brilliant Blue R decolorization by white rot fungi Dichomitus squalens, Ischnoderma resinosum and Pleurotus calyptratus. Chemosphere. 60, 398-404.

Eriksson, T., Börjesson, J., Tjerneld, F. 2002. Mechanism of surfactant effect in enzymatic hydrolysis of lignocelluloses. Enzyme Microb. Techol. 31, 353-364.

Fava, F., Berselli, S., Conte, P., Piccolo, A., Marchetti, L. 2004. Effects of humic substances and soya lecithin on the aerobic bioremediation of a soil historically contaminated by polycyclic aromatic hydrocarbons (PAHs). Biotechnol. Bioeng. 88, 214-223.

Fava, F., Bertin, L., Fedi, S., Zannoni, D. 2003. Methyl- $\beta$-cyclodextrin-enhanced solubilization and aerobic biodegradation of polychlorinated biphenyls in two aged-contaminated soils. Biotechnol. Bioeng. 81, 381-390.
Fava, F., Di Gioia, D. 2001. Soya lecithin effects on the aerobic biodegradation of polychlorinated biphenyls in an artificially contaminated soil. Biotechnol. Bioeng. 72, 177-184.

Flasz, A., Rocha, C.A., Mosquera, B., Sajo, C. 1998. A comparative study of the toxicity of a synthetic surfactant and one produced by Pseudomonas aeruginosa ATCC 55925. Med. Sci. Res. 26, 181185.

Franzetti, A., Bestetti, G., Caredda, P., La Colla, P., Tamburini, E. 2008. Surface-active compounds and their role in the access to hydrocarbons in Gordonia strains. FEMS Microbiol. Ecol. 63, 238-248.

Franzetti, A., Caredda, P., La Colla, P., Pintus, M., Tamburini, E., Papacchini, M., Bestetti, G. 2009. Cultural factors affecting biosurfactants production by Gordonia sp. strain BS29 in soil remediation technologies. Int. Biodeterrioration Biodegr. $63,943-947$.

Franzetti, A., Caredda, P., Ruggeri, C., La Colla, P., Tamburini, E., Papacchini, M., Bestetti, G. 2009. Potential applications of surface active compounds by Gordonia sp. strain BS29 in soil remediation technologies. Chemosphere. 75, 801-807.

Franzetti, A., Di Gennaro, P., Bestetti, G., Lasagni, A., Pitea, D., Collina, E. 2008. Selection of surfactants for enhancing diesel hydrocarbons-contaminated media bioremediation. J. Hazard. Mater. 152, 1309-1316.

Fuguet, E., Ràfols, C., Rosés, M., Bosch, E. 2005. Critical micelle concentration of surfactant in aqueous buffered and unbuffered systems. Anal. Chim. Acta. 548, 95-100.

Gao, Y.Z., Ling, W.T., Zhu, L.Z., Zhao, B.W., Zheng, Q.S. 2007. Surfactant-enhanced phytoremediation of soil contaminated with hydrophobic organic contaminants: Potential and assessment. Pedosphere. 17, 409-418. 
Garon, D., Krivobok, S., Wouessidjewe, D., SeigleMurandi, F. 2002. Influence of surfactants on solubilization and fungal degradation of fluorine. Chemosphere. 47, 303-309.

Gautam, K.K., Tyagi, V.K. 2006. Microbial surfactants: A review. J. Oleo Sci. 55, 155-166.

Gevao, B., Semple, K.T., Jones, K.C. 2000. Bound pesticide residues in soils: a review. Environ. Pollut. 108, 3-14.

Gharaei-Fathabad, E. 2011. Biosurfactant in pharmaceutical industry: A review. Am. J. Drug Discov. Dev. 1, 58-69.

Hamman, O.B., de La Rubia, T., Martínez, J. 1997. Effect of carbon and nitrogen limitation on lignin peroxidase and manganese peroxidase production by Phanerochaete flavido-alba. J. Appl. Microbiol. 83, 751-757.

Hanna, K., Denoyel, R., Beurroies, I., Dubès, J.P. 2005. Solubilization of pentachlorophenol in micelles and confined surfactant phases. Coll. Surf. A: Physicochem. Eng. Aspects. 254, 231-239.

Hatzinger, P.B., Alexander, M. 1995. Effect of aging of chemicals in soil on their biodegradability and extractability. Environ. Sci. Technol. 29, 537-545.

Jain, R.K., Kapur, M., Labana, S., Lal, B., Sarma, P.M., Bhattacharya, D., Thakur, I.S. 2005. Microbial diversity: Application of microorganisms for the biodegradation of xenobiotics. Curr. Sci. 89, 101-112.

Jiménez Islas, D., Medina Moreno, S.A., Gracida Rodríguez, J.N. 2010. Propiedades, aplicaciones y producción de biotensoactivos. Rev. Int. Contam. Ambient. 26, 65-84.

Kang, S.W., Kim, Y.B., Shin, J.D., Kim, E.K. 2010. Enhanced biodegradation of hydrocarbons in soil by microbial biosurfactant, Sophorolipid. Appl. Biochem. Biotechnol. 160, 780-790.
Kim, I.S., Park, J.S., Kim, K.W. 2001. Enhanced biodegradation of polycyclic aromatic hydrocarbons using nonionic surfactants in soil slurry. Appl. Geochem. 16, 1419-1428.

Kim, S.Y., Oh, D.K., Kim, J.H. 1997. Biological modification of hydrophobic group in Acinetobacter calcoaceticus RAG-1 Emulsan. J. Ferment. Bioeng. 84, 162-164.

Kosaric, N. 2001. Biosurfactants and their application for soil bioremediation. Food Technol. Biotechnol. 39, 295-304.

Kosaric, N. 1992. Biosurfactants in industry. Pure Appl. Chem. 64, 1731-1737.

Laha, S., Luthy, R.G. 1991. Inhibition of phenanthrene mineralization by nonionic surfactants in soil-water systems. Environ. Sci. Technol. 25, 1920-1930.

Leonardi, V., Šašek, V., Petruccioli, M., D'Annibale, A., Erbanova, P., Cajthaml, T. 2007. Bioavailability modification and the fungal biodegradation of PAHs in aged industrial soils. Int. Biodeterioration Biodegrad. 60, 165-170.

Leung, P.C., Pointing, S.B. 2002. Effect of different carbon and nitrogen regimes on Poly R decolorization by white-rot fungi. Mycol. Res. 106, 86-92.

Lima, A.S., Alegre, R.M. 2009. Evaluation of emulsifier stability of biosurfactant produced by Saccharomyces lipolytica CCT-0913. Braz. Arch. Biol. Technol. 52, 285-290.

Mata-Sandoval, J.C., Karns, J., Torrents, A. 2002. Influence of rhamnolipids and Triton X-100 on the desorption of pesticides from soils. Environ. Sci. Technol. 36, 4669-4675.

Mouso, N., Papinutti, L., Forchiassin, F. 2003. Efecto combinado del cobre y $\mathrm{pH}$ inicial del medio de cultivo sobre la producción de lacasa y manganeso peroxidasa por Stereum hirsutum (Willd) Pers. Rev. Iberoam. Micol. 20, 176-178. 
Moussa, T.A.A., Ahmed, G.M., Abdel-hamid, S.M.S. 2006. Optimization of cultural conditions for biosurfactants production from Nocardia amarae. J. Appl. Sci. Res. 2, 844-850.

Mukherjee, S., Das, P., Sen, R. 2006. Towards commercial production of microbial surfactants. Trends Biotechnol. 24, 509-515.

Mulder, H., Wassink, G.R., Breure, A.M., van Andel, J.G., Rulkens, W.H. 1998. Effect of nonionic surfactants on naphthalene dissolution and biodegradation. Biotechnol. Bioeng. 60, 397-407.

Mulligan, C.N. 2005. Environmental applications for biosurfactants. Environ. Pollut. 133, 183-198.

Mulligan, C.N., Gibbs, B.F. 1990. Recovery of biosurfactants by ultrafiltration. J. Chem. Technol. Biotechnol. 47, 23-29.

Mulligan, C.N., Yong, R.N., Gibbs, B.F. 2001. Surfactant-enhanced remediation of contaminated soil: a review. Eng. Geol. 60, 371-380.

Muthusamy, K., Gopalakrishnan, S., Ravi, T.K., Sivachidambaram, P. 2008. Biosurfactants: Properties, commercial production and application. Curr. Sci. 94, 736-747.

Navon-Venezia, S., Zosim, Z., Gottlieb, A., Legmann, R., Carmeli, S., Ron, E. Z., Rosenberg, E. 1995. Alasan, a new bioemulsifier from Acinetobacter radioresistens. Appl. Environ. Microbiol. 61, 3240-3244.

Neu, T. 1996. Significance of bacterial surface-active compounds in interaction of bacteria with interfaces. Microbiol. Rev. 60, 151-166.

Nguyen, T.T., Youssef, N.H., McInerney, M. J., Sabatini, D.A. 2008. Rhamnolipid biosurfactant mixtures for environmental remediation. Water Res. 42, 1735-1743.

Ochoa-Loza, F.J., Noordman, W.H., Jannsen, D.B., Brusseau, M.L., Maier, R.M. 2007. Effect of clays, metal oxides, and organic matter on rhamnolipid biosurfactant sorption by soil. Chemosphere. 66, 1634-1642.

Pacwa-Plociniczak, M., Plaza, G.A., PiotrowskaSeget, Z., Cameotra, S.S. 2011. Environmental applications of biosurfactants: Recent Advances. Int. J. Mol. Sci. 12, 633-654.

Patist, A., Bhagwat, S.S., Penfield, K.W., Aikens, P., Shah, D.O. 2000. On the measurement of critical micelle concentrations of pure and technicalgrade nonionic surfactants. J. Surfactants Deterg. 3, 53-58.

Pei, X., Zhan, X., Zhou, L. 2009. Effect of biosurfactant on the sorption of phenanthrene onto original and $\mathrm{H}_{2} \mathrm{O}_{2}$-treated soils. J. Environ. Sci. - China. 21, 1378-1385.

Perfumo, A., Smyth, T.J.P., Marchant, R., Banat, I.M. 2010. Production and roles of biosurfactants and bioemulsifiers in accessing hydrophobic substrates. In: Kenneth N. Timmis (ed.), Handbook of Hydrocarbon and Lipid Microbiology, Springer. UK. 2, 1501-1512.

Plaza, G.A., Lukasik, K., Wypych, J., Nalecz-Jawecki, G., Berry, C., Brigmon, R.L. 2008. Biodegradation of crude oil and distillation products by biosurfactan-producing bacteria. Polish. J. Environ. Stud. 17, 87-94.

Poeton, T., Stensel, H., Strand, S. 1999. Biodegradation of polyaromatic hydrocarbons by marine bacteria: Effects of solid phase on degradation kinetics. Water Res. 33, 868-880.

Pointing, S.B. 2001. Feasibility of bioremediation by white-rot fungi. Appl. Microbiol. Biotechnol. 57, 20-33.

Prak, D.J.L., Pritchard, P.H. 2002. Solubilization of polycyclic aromatic hydrocarbon mixtures in micellar nonionic surfactant solutions. Water Res. $36,3463-3472$. 
Rahman, K.S.M., Gakpe, E. 2008. Production, characterization and applications of biosurfactantsReview. Biotechnology. 7, 360-370.

Reddy, C.A. 1995. The potential for white-rot fungi in the treatment of pollutants. Curr. Opin. Biotechnol. $6,320-328$.

Rigano, L., Lionetti, N., Otero, R. 2009. Quillaja Triterpenic Saponins-The Natural Foamers. SOFWJournal. 135, 2-9.

Rodríguez Couto, S., Rivela, I., Muñoz, M.R., Sanromán, A. 2000. Stimulation of ligninolytic enzyme production and the ability to decolourise Poly R-478 in semi-solid-state cultures of Phanerochaete chrysosporium. Bioresource Technol. 74, 159-164.

Rodríguez-Cruz, M.S., Sánchez-Martín, M.J., Sánchez-Camazano, M. 2004. Enhanced desorption of herbicides sorbed on soils by addition of Triton X-100. J. Environ. Qual. 33, 920-929.

Ron, E. Z., Rosenberg, E. 2002. Biosurfactants and oil bioremediation. Curr. Opin. Biotechnol. 13, 249-252.

Ron, E. Z., Rosenberg, E. 2001. Minireview: natural roles of biosurfactants. Environ. Microbiol. 3, 229-236.

Rosenberg, E., Ron, E.Z. 1999. High- and low-molecular-mass microbial surfactants. Appl. Microbiol. Biotechnol. 52, 154-162.

Rubilar, O., Diez, M.C., Gianfreda, L. 2008. Transformation of chlorinated phenolic compounds by white rot fungi. Crit. Rev. Environ. Sci. Technol. 38, 227-268.

Rubilar, O., Tortella, G., Cea, M., Acevedo, F., Bustamante, M., Gianfreda, L., Diez, M.C. 2011. Bioremediation of a Chilean Andisol contaminated with pentachlorophenol (PCP) by solid substrate cultures of white rot fungi. Biodegradation. 22, 31-41.
Rufino, R.D., Rodrigues, G.I.B., Campos-Takaki, G.M., Sarubbo, L.A., Ferreira, S.R.M. 2011. Application of a yeast biosurfactant in the removal of heavy metals and hydrophobic contaminant in a soil used as slurry barrier. Appl. Environ. Soil Sci. doi:10.1155/2011/939648.

Saichek, R.E., Reddy, K.R. 2004. Evaluation of surfactants/ cosolvents for desorption/solubilization of phenanthrene in clayey soils. Int. J. Environ. Stud. 61, 587-604.

Semple, K.T., Morris, A.W.J., Paton, G.I. 2003. Bioavailability of hydrophobic organic contaminants in soils: fundamental concepts and techniques for analysis. Eur. J. Soil Sci. 54, 809-818.

Shete, A.M., Wadhawa, G., Banat, I.M., Chopade, B.A. 2006. Mapping of patents on bioemulsifiers and biosurfactant: A review. J. Sci. Ind. Res. 65, 91-115.

Shin, K.H., Kim, K.W., Ahn, Y. 2006. Use of biosurfactant to remediate phenanthrene-contaminated soil by the combined solubilization-biodegradation process. J. Hazard. Mater. B137, 1831-1837.

Singh, A., Van Hamme, J.D., Ward, O. P. 2007. Surfactants in microbiology and biotechnology: Part 2. Application Aspects. Biotechnol. Adv. 25, 99121.

Soeder, C.J., Papaderos, A., Kleespies, M., Kneifel, H., Haegel, F.H., Webb, L. 1996. Influence of pythogenic surfactants (quillaya saponin and soya lecithin) on bio-elimination of phenanthrene and fluoranthene by three bacteria. Appl. Microbiol. Biotechnol. 44, 654-659.

Tang, W.C., White, J.C., Alexander, M. 1998. Utilization of sorbed compounds by microorganisms specifically isolated for that purpose. Appl. Microbiol. Biotechnol. 49, 117-121.

Tecon, R., van der Meer, J.R. 2010. Effect to types of biosurfactants on phenanthrene availability to 
the bacterial bioreporter Burkholderia sartisoli strain RP037. Appl. Microbiol. Biotechnol. 85, 1131-1139.

Tiehm, A. 1994. Degradation of polycyclic aromatic hydrocarbons in the presence of synthetic surfactants. Appl. Environ. Microbiol. 60, 258-263.

Toledo, F.L., González-López, J., Calvo, C. 2008. Production of bioemulsifier by Bacillus subtilis, Alcaligenes faecalis and Enterobacter species in liquid culture. Bioresour. Technol. 99, 8470-8475.

Tortella, G.R., Durán, N., Diez, M.C. 2005. Fungal diversity and use in decomposition of environmental pollutants. Crit. Rev. Microbiol. 31, 197-212.

Ürek, R.Ö., Pazarlioğlu, N.K. 2005. Production and stimulation of manganese peroxidase by immobilized Phanerochaete chrysosporium. Proceedings Biochemistry. 40, 83-87.

Urum, K., Pekdemir, T. 2004. Evaluation of biosurfactant for crude oil contaminated soil washing. Chemosphere. 57, 1139-1150.

Van Dyke, M. I., Couture, P., Brauer, M., Lee, H., Trevors, J.T. 1993. Pseudomonas aeruginosa UG2 rhamnolipid biosurfactants: structural characterization and their use in removing hydrophobic compounds from soil. Can. J. Microbiol. 39, 1071-1078.

Van Hamme, J.D., Singh, A., Ward, O.P. 2006. Physiological aspects. Part 1 in a series of papers devoted to surfactants in microbiology and biotechnology. Biotechnol. Adv. 24, 604-620.

Vidali, M. 2001. Bioremediation. An overview. Pure Appl. Chem. 73, 1163-1172.

Volkering, F., Breure, A.M., Rulkens, W.H. 1998. Microbiological aspects of surfactant use for biological soil remediation. Biodegradation. 8, 401-417.

Volkering. F, Breure, A.M., van Andel, J.G., Rulkens, W.H. 1995. Influence of nonioinic surfactants on bioavailability and biodegradation of polycyclic aromatic hydrocarbons. Appl. Environ. Microbiol. 61, 1699-1705.

Wang, P., Hu, X., Cook, S., Begonia, M., Lee, K.S., Hwang, H.M. 2008. Effect of culture conditions on the production of ligninolytic enzymes by rot fungi Phanerochaete chrysosporium (ATCC 20696) and separation of its lignin peroxidase. World J. Microbiol. Biotechnol. 24, 2205-2212.

Wattanaphon, H.T., Kerdsin, A., Thammacharoen, C., Sangvanich, P., Vangnai, A.S. 2008. A biosurfactant from Burkholderia cenocepacia BSP3 and its enhancement of pesticide solubilization. J. Appl. Microbiol. 105, 416-423.

West, C.C., Harwell, J.H. 1992. Surfactants and subsurface remediation. Environ. Sci. Technol. 26, 2324-2330.

Whang, L.M., Liu, P.W., Ma, C.C., Cheng, S.S. 2008. Application of biosurfactants, rhamnolipid, and surfactin, for enhanced biodegradation of dieselcontaminated water and soil. J. Hazard. Mater. 151, 155-163.

Wong, J.W.C., Fang, M., Zhao, Z., Xing, B. 2004. Effect of surfactants on solubilization and degradation of phenanthrene under thermophilic conditions. J. Environ. Qual. 33, 2015-2025.

Xie, Y.W., Li, Y., Ye, R.Q. 2005. Effect of alcohols on the phase behavior of microemulsions formed by a biosurfactant-rhamnolipid. J. Disper. Sci. Technol. 26, 455-461.

Xu, J., Yuan, X., Dai, S. 2006. Effect of surfactant on desorption of aldicarb from spiked soil. Chemosphere. 62, 1630-1635.

Yamanaka, R., Soares, C.F., Matheous, D.R., Macahdo, K.M.G. 2008. Lignolytic enzymes produced by Trametes villosa $\mathrm{CCB} 176$ under different culture conditions. Braz. J. Microbiol. 39, 78-84.

Yeom, I.T., Ghosh, M.M., Cox, C.D. 1996. Kinetic aspects of surfactant solubilization of soil-bound 
polycyclic aromatic hydrocarbons. Environ. Sci. Technol. 30, 1589-1595.

Yu, H., Zhu, L., Zhou, W. 2007. Enhanced desorption and biodegradation of phenanthrene in soil-water systems with the presence of anionic-nonionic mixed surfactants. J. Hazard. Mater. 142, 354361.

Zana, R. 2005. Dynamics of surfactant self-assemblies: Micelles, microemulsions, vesicles, and lyotropic phases. Surfactant Science Series. CRC Press, Boca Raton, FL, 125, 12-13.

Zhou, J., Jian, W.Y., Ding, J. A., Zhang, X.D., Gao, S.X. 2007. Effect of Tween 80 and beta-cyclodextrin on degradation of decaboromodiphenyl ether
(BDE-209) by white-rot fungi. Chemosphere. 70 , 172-177.

Zhou, W., Zhu, L. 2008. Enhanced soil flushing of phenantrene by anionic-nonionic mixed surfactant. Water Res. 42, 101-108.

Zhu, L., Feng, S. 2003. Synergistic solubilization of polycyclic aromatic hydrocarbons by mixed anionic-nonionic surfactants. Chemosphere. 53, 459-467.

Zouboulis, A.I., Matis, K.A., Lazaridis, N.K., Golyshin, P.N. 2003. The use of biosurfactant in flotation: application for the removal of metal ions. Minerals Engineering. 16, 1231-1236. 
